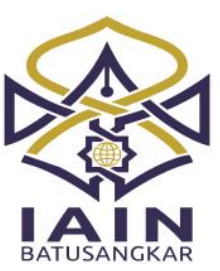

\title{
The Levels of Questions Used on Reading Test with Regards to Revised Bloom's Taxonomy
}

\author{
Yenni Kurnia Fitri*) \\ Universitas Negeri Padang, \\ Sumatera Barat, Indonesia \\ Email: yennikf86@gmail.com
}

\section{Hermawati Syarif* \\ Universitas Negeri Padang, \\ Sumatera Barat, Indonesia \\ Email: hermawati_sy@yahoo.com}

\section{Desvalini Anwar*}

Universitas Negeri Padang,

Sumatera Barat, Indonesia

Email: desvalinianwar@yahoo.com

*) Corresponding Author

\begin{abstract}
The research aims to find out the levels of questions used by an English teacher for mid-semester reading test for the second graders in SMA 2 Padang in accordance Anderson's and Karthwohl's taxonomy (2001). The participant was chosen based on purposive sampling. This is a descriptive research. The data of the research were obtained from documents analysis. Evaluation of the question sheets were analyzed one by one. After that, the data were analyzed, grouped, and explained based on the research aims. The results of this research show that the teacher formulated on three levels of questions. They are the questions remembering (46.67\%), understanding (36.66\%), and applying (16.67\%). From the result, it can be concluded almost half of the questions are in the form of remembering and least of them for applying.
\end{abstract}

Kata Kunci: Reading Test, levels of question, Anderson's and Karthwohl's taxonomy

\section{INTRODUCTION}

I $\mathrm{n}$ constructing mid-semester reading test, the teachers should consider level of questions that assosiates with the degree of question difficulty to diffrentiate the question from the lower level to the highest one. The levels used was the revision of Bloom's taxonomy proposed by Anderson \& Krathwohl (2001) taxonomy that divides it into six levels; remembering, understanding, applying, analyzing, evaluating, and creating. All those levels should have been given to senior high school because their cognitive skill has reached that level. It is based on the cognitive stages that are proposed by Piaget in Brown (2007) that senior high school students belong to part of adolescence who should achieve the highest stage of cognitive development. It is in line with the level of competency for senior high school students that reach creating level. Thus, it can be assumed that the teachers should provide the reading test with all levels of questions from remembering to creating level. However, due to the primarily research conducted at SMAN 2 Padang, it was found that most of the questions were chosen to know the students' ability to remember the information in the text, check students' ability to memorize the information in the text, find out the students' knowledge of vocabulary, and assess students' understanding of the text. All those objectives were grouped into low level questions. It means that the teacher used lowlevel questions in mid-semester reading test.

There are a number of researchers who had observed examination based on Bloom's taxonomy, questions in the classroom classified into Bloom's Taxonomy, learning objectives using Bloom's Taxonomy, and English reading test. They are Karamustafaoğlu (2003), Fiprinita (2007)), Mantyi-Ncube \& Hlophe, (2011). All the researches above have similarities and differences with this research. Some of the researches have similarity in the use of Bloom's Taxonomy to investigate the variable of the research. The researchers that 
used Bloom's Taxonomy are Karamustafaoğlu, Fiprina, Mantyi-Ncube and Hlope, and Fitri.

The differences of this research with the previous researches are subjects of the study, types of test analysis, and the use of the taxonomy. Karamustafaoğlu investigated natural science test. Another researcher, Mantyi-Ncube and Hlophe investigated Home Economic teachers, teach and test their students. The other researchers observed Bloom's Taxonomy related to the classroom interaction, learning objectives and textbooks as Fipriani and Fitria done. This research is going to observe different variable from the previous researches that is the level of the question in English Midsemester exam at senior high school by usng revised Bloom's taxonomy proposed by Anderson \& Krathwohl (2001).

The questions that are inappropriate with the students' level that should have been achieved will have a great impact for the students in developing their English language competence. Moreover, students are the reflection of national education quality. By observing the ability of the students, the quality of the education can be known. If the students' cognitive ability is low, this will reflect the poor quality of education as well. Thus, it is important for the teachers to design the test with higher levels of questions in order to activate their cognitive competence. Based on this explanation, the level of the teachers' questions needs to be investigated to know the level of teachers' questions and the difficulties faced in designing the test. The level of the questions in the test is considered less appropriate with the students because it is not suitable with their level of cognitive skill. Since it does not match with the students, the cognitive skill that should have been achieved by senior high school students cannot be obtained. In other word, the students still have low level of cognitive skills. This is the reason why this research is important to be conducted in order to find out the level of the teachers' questions in mid-semester reading test at senior high school.

\section{METHOD}

The research was conducted by using descriptive design. Gall \& Borg (2003) state that a descriptive research involves describing characteristics of a particular sample of individuals or other phenomena. Thus, the result of this research was presented in the form of description about the levels of questions in mid-semester reading test.

The object of the research was the English teacher that compiled the reading test for third grade at SMAN 2 Padang. The selection of the participants was based on purposive sampling. As Calmorin \& Calmorin, (2007) state that purposive sampling is used based on the aim of the researcher to select the individuals as samples that suitable with his research. Thus, by using this sampling, it helped the researcher to choose the sample that was suitable for the purpose of the research.

Evaluation sheet of document was the instrument of this research that is used to get the valid levels of questions compiled by the teachers. It was consulted to the inter-raters to find out the consistency of the instrument before it was used. The evaluation sheet was fulfilled through analyzing document, the print out of mid-semester exam at the third grade. Every question was decided to belong for a certain level based on its characteristic and then calculated the amount of questions for each level. the result of the evaluation has been consulted to evaluator to get the reliability result.

\section{RESULT AND DISCUSSION \\ Revised Bloom's Taxonomy}

There are many types of questions that can be used by a teacher to assess students' ability. Those questions are grouped into six levels as proposed by Bloom (1956) who is the first expert that proposed the levels of the questions. Bloom (1956) proposes six levels of cognitive 
domain to help the development of the thinking process from the simple to the complex thought. These questions are categorized into two major levels; low and high levels as mentioned by Goodwin (1992). He gives more complex explanation about these major types that low-level questions consist of knowledge, comprehension, and application and highlevel questions consist of analysis, synthesis, and evaluation. The levels of questions show the hierarchy of the questions from the easy one to the most difficult or called the degree of questions difficulty.

The levels of questions proposed by Bloom (1956) were revised by Anderson and Karthwohl (2001). The numbers of the levels are still the same. However; they changed the form of the levels from noun to verb in order to make them active process. They also changed the form of synthesize to creating and shifted it into the last level with the consideration of producing something should be the highest level. The levels are remembering, understanding, applying, analyzing, evaluating, and creating.

Remembering is the lowest level that is retrieving relevant knowledge from longterm memory. Forehand (2012) mentions remembering as retrieving, recognizing, and recalling relevant knowledge in long term memory. Remembering is divided into two sub-cognitive levels; recognizing and recalling. Recognizing is locating knowledge in long-term memory that is consistent with presented material and recalling is retrieving relevant knowledge from long-term memory. Banks (2012) explains more about recognizing that is identifying an action or event with prompt and recalling is a step beyond recognizing that there is no external stimulus or list to help memorial retrieval.

Understanding is determining meaning of instructional messages, including oral, written, and graphic communication. This definition is similar with definition given by Pickard (2007), Chi Duc (2008), and forehand (2012) that understanding is constructing meaning from information and concept. Understanding has seven divisions; interpreting, exemplifying, classifying, summarizing, inferring, comparing, and explaining. Interpreting is transforming gained information to another form. Exemplifying is finding a specific example or instance of a general concept or principle. Classifying is determining that something belongs to a certain category. Summarizing is producing a short statement that represents presented information or abstracts a general theme. Inferring is drawing a logical conclusion from presented information. Comparing is detecting similarities and differences between two or more objects, events, ideas, problems, or situations. Explaining is constructing and using a causeand-effect model of a system or series.

Applying refers to carry out or use a procedure in given situation. Chi Duc (2008) defines applying as using information in another familiar situation. This level is divided into executing, or implementing. Executing is applying a procedure to a familiar task and implementing is applying one or more procedures to an unfamiliar task.

Analyzing is the first level in the highest level of question. It is breaking material into constituent parts, determining how the parts relate to one another and to an overall structure or purpose through differentiating, organizing, and attributing. This definition is also the same with Chi Duc (2008) that analyzing is breaking information into parts to explore understanding and relationships. Differentiating is discriminating relevant from irrelevant parts or important from unimportant parts of presented material. Organizing is determining how elements fit or function within a structure. Attributing is determining the point of view, biases, values, or intent underlying presented material.

Evaluating is making judgments based on criteria and standards. Richlin (2006), and (Munzenmaier, 2013) also agree with this definition of evaluating. Checking is detecting inconsistencies or mistake within a process or product, determining whether a 
process or product has internal consistency, or detecting the effectiveness of a procedure as it is being implemented. Critiquing is detecting inconsistencies between a product or operation and some external criteria, determining whether a product has external consistency, or judging the appropriateness of a procedure for a given problem.

Creating is the last level of questions that is the highest level. It is putting elements together to form a coherent or functional whole and reorganize elements into a new pattern or structure through generating, planning, or producing. Chi Duc (2008) almost has the same definition of creating defined by Anderson and Karthwohl (2001) that creating is generating ideas, products or ways of viewing things. Generating is inventing alternative hypotheses based on criteria or called hypothesizing. Planning is devising a method for accomplishing some task or called designing. Producing is inventing a product or called constructing. All these levels of questions are the classification of thinking or complexity of cognitive domain that deals with development of intellectual abilities and skills.

\section{Percentage of Question Levels for Reading Test}

Zimmaro (2004) proposes the percentage of the levels of questions for 40 questions that is separated into 5 questions $(12.5 \%)$ for knowledge, 7 questions $(17.5 \%)$ for comprehension, 15 questions $(37.5 \%)$ for application, 10 questions (25\%) for analysis, 2 questions (5\%) for synthesis and 1 question $(2.5 \%)$ for evaluation. He gives more description about the percentage of the levels of questions for four topics in test blueprint in the following table:

\begin{tabular}{|l|l|l|l|l|c|}
\hline & $\begin{array}{c}\text { Topic } \\
\mathrm{A}\end{array}$ & $\begin{array}{c}\text { Topic } \\
\mathrm{B}\end{array}$ & $\begin{array}{c}\text { Topic } \\
\mathrm{C}\end{array}$ & $\begin{array}{c}\text { Topic } \\
\mathrm{D}\end{array}$ & Total \\
\hline Knowledge & 1 & 2 & 1 & 1 & $\begin{array}{c}5 \\
(12.5 \%)\end{array}$ \\
\hline Comprehension & 2 & 1 & 2 & 2 & $\begin{array}{c}7 \\
(17.5 \%)\end{array}$ \\
\hline Application & 4 & 4 & 3 & 4 & $\begin{array}{c}15 \\
(37.5 \%)\end{array}$ \\
\hline Analysis & 3 & 2 & 3 & 2 & $\begin{array}{c}10 \\
(25 \%)\end{array}$ \\
\hline Synthesis & & 1 & & 1 & $\begin{array}{c}2 \\
(5 \%)\end{array}$ \\
\hline
\end{tabular}

\begin{tabular}{|l|c|c|c|l|c|}
\hline & $\begin{array}{c}\text { Topic } \\
\mathrm{A}\end{array}$ & $\begin{array}{c}\text { Topic } \\
\mathrm{B}\end{array}$ & $\begin{array}{c}\text { Topic } \\
\mathrm{C}\end{array}$ & $\begin{array}{c}\text { Topic } \\
\mathrm{D}\end{array}$ & Total \\
\hline Evaluation & & & 1 & & $\begin{array}{c}1 \\
(2.5 \%)\end{array}$ \\
\hline Total & 10 & 10 & 10 & 10 & 40 \\
$(25 \%)$ & $(25 \%)$ & $(25 \%)$ & $(25 \%)$ & $(100 \%)$ \\
\hline \multicolumn{6}{|c|}{ Source: Zimmaro (2004) }
\end{tabular}

From these degrees of questions, it can be seen that the highest percentage is application question and the lowest one is evaluation. These percentages can be used by the teachers as a guidance of designing a test with a right portion for the students. They can still be used for revised Bloom since the aim of each level is still the same. The differences are the levels on revised Bloom are specified into sub-levels and the position of the fifth and the last levels changed. Before, synthesis is the fifth level and evaluation is the last one. On revised Bloom synthesizing is the last level and evaluating is the fifth one.

The levels of Questions Used by Teacher for Reading Test Based on Revised Bloom's Taxonomy.

The result of the evaluation sheet of document could be seen in the table below:

\begin{tabular}{|c|c|c|c|}
\hline Levels & Sub-levels & $\begin{array}{c}\text { Percentage } \\
(\%)\end{array}$ & $\begin{array}{c}\text { Total Percentge } \\
(\%)\end{array}$ \\
\hline \multirow[t]{2}{*}{ Remembering } & Recognizing & $46.67 \%$ & \multirow{2}{*}{$46.67 \%$} \\
\hline & Recalling & - & \\
\hline \multirow[t]{7}{*}{ Understanding } & Interpreting & $13.33 \%$ & \multirow{7}{*}{$36.66 \%$} \\
\hline & Exemplifying & & \\
\hline & Classifying & $13.33 \%$ & \\
\hline & Summarizing & & \\
\hline & Inferring & $6.7 \%$ & \\
\hline & Comparing & & \\
\hline & Explaining & $3.3 \%$ & \\
\hline \multirow[t]{2}{*}{ Applying } & Executing & - & \multirow{2}{*}{$16.67 \%$} \\
\hline & Implementing & $16.67 \%$ & \\
\hline \multirow[t]{3}{*}{ Analyzing } & Differentiating & - & \multirow{3}{*}{-} \\
\hline & Organizing & - & \\
\hline & Attributing & - & \\
\hline \multirow[t]{2}{*}{ Evaluating } & Checking & - & \\
\hline & Critiquing & - & \\
\hline \multirow[t]{3}{*}{ Creating } & Generating & - & \multirow{3}{*}{-} \\
\hline & Planning & - & \\
\hline & Producing & - & \\
\hline \multicolumn{2}{|l|}{ Total } & $100 \%$ & $100 \%$ \\
\hline
\end{tabular}

The table above shows the levels of the questions designed by the teacher for midsemester reading test. There were three of six levels formulated by Anderson and Karthwohl (2001) found in the test. They are remembering, understanding and applying. The highest percentage is remembering that almost half of the questions were formulated in this level. The lowest percentage is 
applying. The questions found for this level were less than $20 \%$ of all questions. It can be assumed that the teacher paid more attention to remembering level than other levels.

The table also shows that not all sublevels of the questions were included in the test. At remembering level, there are two sub-levels of questions, recognizing and recalling; however, there was only one sublevel found that is recognizing. It was also happened to understanding level that has 7 sub-levels, interpreting, exemplifying, classifying, summarizing, inferring, comparing and explaining. There were 4 sublevels created the questions by the teacher. The last level that included in the test, applying, was also not all the levels found. From two sub-levels, executing and implementing, the teacher only designed the question for implementing.

Not All the levels of Questions Designed by Teacher for Reading Test Based on Revised Bloom's Taxonomy were included.

On revised Bloom's taxonomy by Anderson and Karthwohl (2001), there were six levels of questions; remembering, understanding, applying, analyzing, evaluating, and creating. All of them should be included in the test for senior high school students because senior high school students are grouped as part of adolescence category or formal operational by Piaget in Brown (2007) that is the highest stage of cognitive development. He explains more that the characteristics of adolescents are thinking multiple variables in systematic ways, formulate hypotheses, and think about abstract relationships and concepts. Therefore, the teachers should include all the levels. In fact, the teacher made the questions for three levels, remembering, understanding, and applying. These levels are group into low-level questions as Goodwin (1992) states that lower level questions are knowledge, comprehension, and application.
Not all sub-levels of questions designed by teacher for reading test based on revised Bloom's taxonomy were compiled.

Every level on revised Bloom's taxonomy has sub-levels that are also important to include in the test. Nevertheless; not all sub-levels of the questions were found. There are two sub-levels in remembering level; recognizing and recalling, but only recognizing was found in test. In understanding level, the teacher designed the questions in four sub-levels out of seven. In applying level, there are two sub-levels; executing and implementing. The teacher only made the question for implementing. Actually, all the sub-levels could be included in the test as Zimmaro (2004) proposed the percentage for all levels from 40 questions that knowledge gets $12.5 \%$ (5 questions), comprehension $17.5 \%$ (7 questions), application $37.5 \% \quad(15$ questions), Based on these, the teacher could write all questions for every sub-level. She/he can divide them into 2 and 3 questions for every sub-level in remembering. It means that both recognizing and recalling sub-levels can also be made the questions. The teacher can also include all sub-levels of questions in understanding by providing 1 question for every sub-level. In applying, the teacher can give 7 and 8 questions for every sub-level.

\section{CONCLUSION}

From the result of the research, it can be concluded that the teacher did not include all levels of questions in the reading test for senior high school students. Three of six levels were found in the test; remembering, understanding, and applying. Most of the questions were in the form of remembering and least of them were in applying form. Every level has sub-levels and not all of them were also written the questions. One of two sub-levels at remembering, four of seven sub-levels at understanding and one of two sub-levels at applying were gotten in the test.

Based on the research finding, there are several suggestions that the researcher would 
like to propose. They are: (1) the researcher suggests that the teacher could use the result of this research to produce a test that appropriate for the students, (2) it is expected that the result of this research could be used as a source to do other researches on reading test, (3) and other researchers could continue this research to find out more problems and causes of the problems in designing midsemester reading test.

\section{REFERENCES}

Anderson, L. W., \& Krathwohl, D. R. (2001). A Taxonomy for Learning, Teaching, and Assessing: A Revision of Bloom's Taxonomy of Educational Objectives. New York: Longmans.

Banks, S. R. (2012). Classroom Assessment: Issues and Practices. Illinois: Waveland Press.

Bloom, B. S. (1956). Taxonomy of Educational Objectives. United States of America: Longmans.

Brown, H. D. (2007). Principles of Language Learning and Teaching. New York: Pearson Education.

Calmorin, L. P., \& Calmorin, M. A. (2007). Research Methods and Thesis Writing. Quezon City: Rex Printing Company, Inc.

Chi Duc, N. (2008). Using Bloom's Taxonomy to Design in-class Reading Questions for Intermediate Students in the Context of Vietnam. VNU Journal of Science, Foreign Languages, 24, 175183.

Fiprinita, R. (2007). Types of Question Asked by Teachers in Classroom Interactions. Unpublished Thesis. Padang: Universitas Negeri Padang.

Forehand, M. (2012). Bloom's Taxonomy: from Emerging Perspectives on learning, Teaching and Technology.
Retrieved on January 10th, 2015 pdf.

Gall, M. D., \& Borg. (2003). Educational Research: An Introduction. Boston: Pearson Education, Inc.

Goodwin, S. . (1992). Effective Classroom Questioning. Urbana-Champaign: office of instructional and managements, University of Illionis.

Karamustafaoğlu, S. (2003). Analysis of Turkish High-School ChemistryExamination Questions According to Bloom's Taxonomy. Chemistry Education: Research and Practice, 4(1), 25-30.

Mantyi-Ncube, B., \& Hlophe, N. (2011). Teaching Testing Higher Cognitive Skills: A Case of Selected High Schools in Swaziland 10-029/AWB/2011/7-263-68. Journal of Agriculture \& Social Sciences.

Munzenmaier, C. and N. R. (2013). Bloom's Taxonomy What's Old Is New Again. The Learning Guild Research. Retrieved on February 20th, 2014 at http://onlineteachered.mit.edu/edcpakistan/files/best-practices/session2/Pre-Session-Munzenmaier-Rubin2013.pdf.

Pickard, M. J. (2007). The New Bloom's Taxonomy: An Overview for Family and Consumer Sciences. Journal of Family and Consumer Sciences Education, 25(1).

Richlin, L. (2006). Blueprint for Learning: Constructing College Courses to Facilitate, Assess, and Document Learning. Virginia: Stylus Publishing.

Zimmaro, D. M. (2004). Writing Good Multiple-Choice Exams. The University of Texas. Retrieved on March 12, 2013 